\title{
Improving the cutting performance of coated tools via appropriate pre- and post-treatments
}

\author{
Konstantinos Bouzakis ${ }^{1,2}{ }^{*}$, Georgios Skordaris ${ }^{1,2}$, Emmanuil Bouzakis ${ }^{2,3}$ and Tilemachos \\ Kotsanis $^{1,2}$ \\ ${ }^{1}$ Laboratory for Machine Tools and Manufacturing Engineering, Mechanical Engineering \\ Department, Aristotle University of Thessaloniki, Greece \\ ${ }^{2}$ Fraunhofer Project Centre Coatings in Manufacturing, in LMTME and in Fraunhofer Institute for \\ Production Technology in Aachen, Germany \\ ${ }^{3}$ German University of Technology in Oman, Department of Engineering, Oman
}

\begin{abstract}
The cutting performance of PVD coated tools can be significantly improved by appropriate pre- and post- treatments of the substrates and coated surfaces respectively. Substrate pre-treatments aim, among others, at improving the coating adhesion. In this way, lower coating loads develop during cutting leading to a decelerated wear evolution. Furthermore, the potential to increase the wear resistance of coated tools via micro-blasting is presented. Micro-blasting parameters such as of grain material, pressure, dry or wet etc., affect significantly the superficial coatings' hardness and brittleness and in this way their wear behaviour. To check the effectiveness of all these methods, innovative coating's characterization procedures providing information concerning the film and substrate properties as well as adhesion are applied, thus reducing the required experimentation time.
\end{abstract}

\section{Introduction}

The increasing manufacturing demands, being supported by the improved capabilities of modern machine tools, require the persistent evolution of superior materials and coatings for cutting tools $[1,2]$. For producing coated tools characterized by enhanced mechanical properties, the integration of various procedures before and after the coating deposition is necessary, as schematically shown in figure 1 . In this context, the conduct of micro-blasting on cemented carbide substrates prior to the coating deposition has been showcased as an emerging technology capable to ensure sufficient film adhesion and prolonged coated tool life $[1,3]$. Macro-blasting on cemented carbide substrates has been also proved as an efficient method for reconditioning coated cemented carbide tools $[1,4,5]$. The conduct of micro-blasting on the already coated surfaces has been documented as an efficient method for improving further the coated tool life [6,7,8,9,10,11,12,13]. For assessing the effectiveness of all these methods, innovative coating's characterization procedures providing information concerning the film and substrate properties as well as adhesion have to be applied [1].

\footnotetext{
* Corresponding author: bouzakis@eng.auth.gr
} 


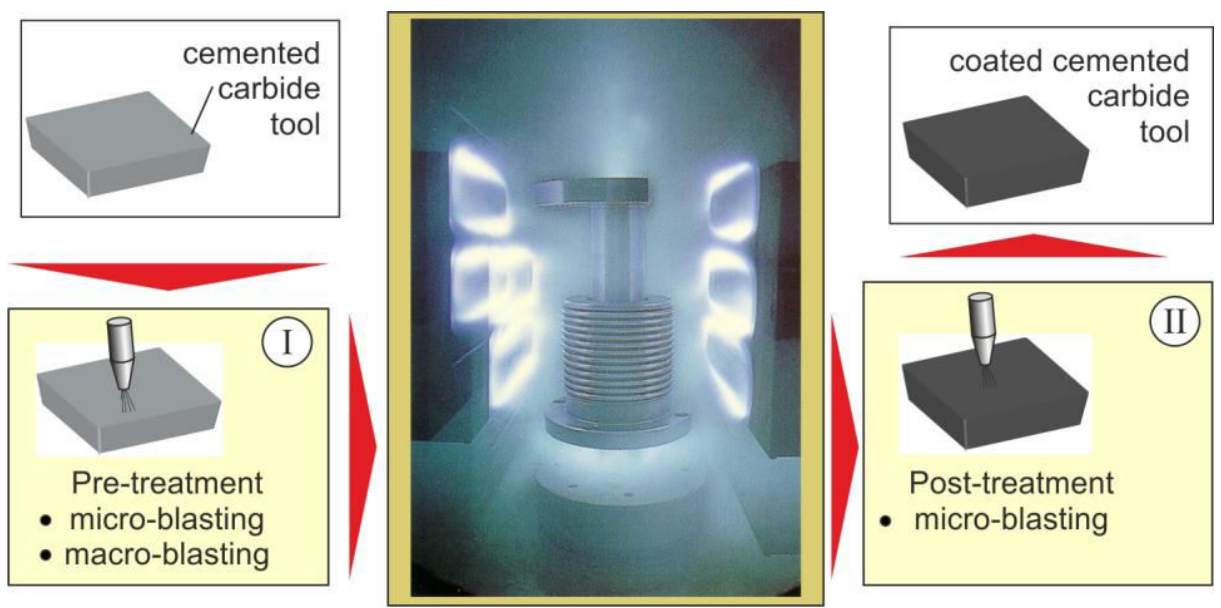

Fig. 1. Schematic presentation of the manufacturing chain to produce coated tools with improved properties.

\section{Substrate's pre-treatments}

\subsection{Micro-blasting for improving the film adhesion}

The coating adhesion and subsequent the cutting performance of coated cemented carbide tools depends significantly on the applied mechanical pre-treatments. Micro-blasting of ground or polished substrates is an efficient method for improving film adhesion. This can be explained considering the effect of micro-blasting on the surface morphology, as it is presented schematically in figure 2a. Superficial residual stresses are induced mainly due to the Co-binder deformation. Moreover, an increase of the micro-roughness occurs. The individual carbides are revealed through the Co-binder removal from the cemented carbide surfaces. In this way it can be assumed that during the film deposition the nucleation rate of potentially formed transient junctions such as TiAlCN on the cobalt free WC-carbide surfaces is increased. Hence, an adhesion improvement between the substrate and the PVD film occurs, since, additionally, the less adhesive Co-regions on the substrate surface decrease [3]. After polishing by disc lapping, the carbides are rounded, the Co free WCsurfaces restricted and the Co-regions increased, thus deteriorating the film adhesion. Through micro-blasting of the polished insert surfaces, the described advantages of microblasting can be re-obtained. In addition, the WC carbides are now better embedded in the Co binder, due to the lower Rt micro-roughness in comparison to ground substrates.

The coating's adhesion of variously treated substrates was evaluated with the aid of the inclined impact test [3]. During this test, significant shear stresses are developed in the film-substrate interface. If these stresses exceed the interfacial toughness, a film overstressing occurs leading to its failure and rapid removal. Figure $2 \mathrm{~b}$ demonstrates the coating failed region versus the number of impacts, during this test. Ground, polished and micro-blasted substrates were investigated, all coated with the same PVD film. The coated inserts, subjected to substrate micro-blasting, withstand more effective the applied loads and have a slower coating failed area ratio FR increase. Moreover, the removal of a pooradherent coating on a polished insert possesses the most intense fracture propagation due to restricted film substrate mechanical interlocking. The highest wear resistance exhibits the coated insert with micro-blasted and polished substrate. These results are mirrored in the SEM micrographs, in the lower part of figure $2 b$ and can be easily interpreted considering the dependencies described in figure $2 \mathrm{a}$. 


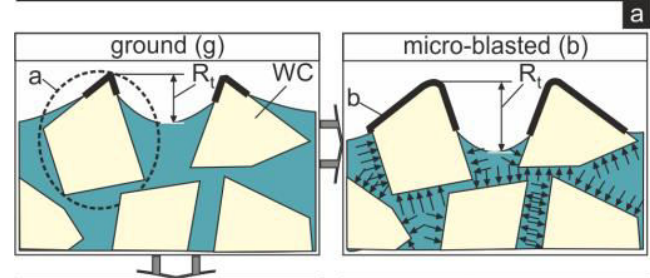

polished by disc lapping (p)

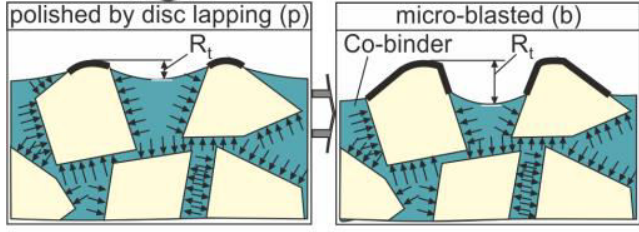

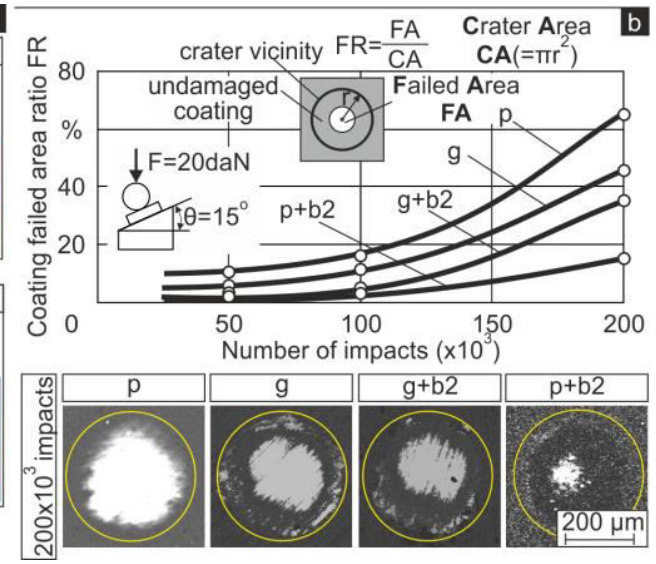

Fig. 2. (a) Micro-blasting and lapping effects on cemented carbide superficial structure. (b) Coating failed area ratio FR propagation in the inclined impact test.

The coating adhesion improvement leads to a significant cutting performance increase, as exhibited in figure $3 \mathrm{a}$. These results were achieved through milling investigations. The coated inserts with ground and micro-blasted substrates reach a tool life of approximately $55 \times 10^{3}$ cuts, at a flank wear width of $0.2 \mathrm{~mm}$. Moreover, the results exhibit a further increase in wear resistance, by means of polishing and subsequent micro-blasting of the substrate. On the other hand, inserts with polished or ground substrates managed to cut only ca. $28 \times 10^{3}$ and $35 \times 10^{3}$, respectively, up to the same flank wear width. Moreover, based on a developed FEM model to simulate the coating-substrate interface adhesion strength by means of appropriate contact elements, the quantification of the film's adhesion properties was enabled via the contact stiffness ratio CSR [1]. In this way, the contribution of various substrate treatments to the film adhesion can be captured. In figure $3 \mathrm{~b}$, the remaining area ratio (1-FR) after $200 \times 10^{3}$ impacts and the contact stiffness ratio CSR in each substrate treatment case are presented.

\subsection{Application of macro-blasting during reconditioning cemented carbide substrates}

In contrast to simple cutting inserts solid tools like milling cutters, gear hobs and gear shaping wheel cutters, broaching tools, etc., have to be reconditioned after achieving the wear limit, due to their elevated cost compared to cutting inserts. The potential of reconditioning worn coated cemented carbide and high speed steel tools through sequential

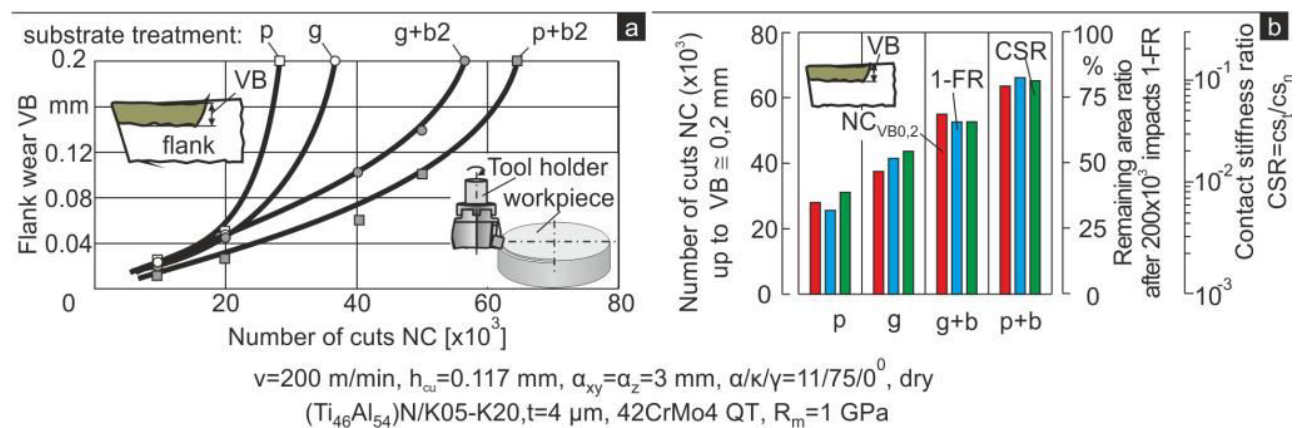

Fig. 3. (a) Flank wear development at various cutting edge pre-treatments. (b) Micro-blasting and pretreatments effects on the film adhesion and coated tool life. 


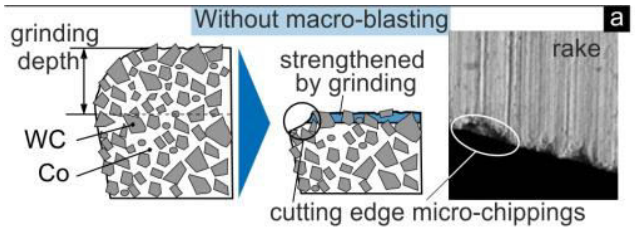

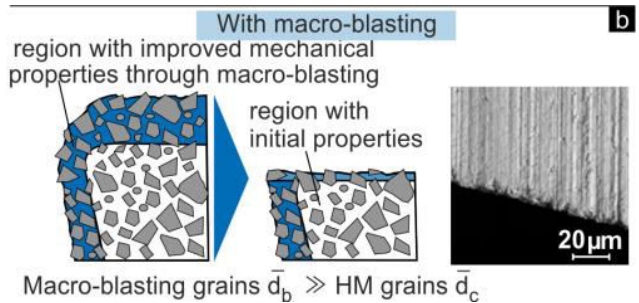

Fig. 4. Effect of macro-blasting and regrinding of the hob tooth rakes on the cutting edge sharpness.

electro-chemical coating removal, tooth rake regrinding, micro-blasting and PVD recoating has a wide industrial importance [4]. However, the effect of all these sequential procedures on the mechanical properties, the cutting-edge sharpness and cutting performance, especially when recoated cemented carbide tools are employed, has to be considered. More specifically, the HM substrates mechanical properties diminishing due to material annealing could be significant after the film re-deposition. In this way, an impairment of carbide grains holding by cobalt binder develops and cutting edge chippings may appear during grinding, as it is schematically demonstrated in figure 4a. This mechanism may decrease the cutting performance of a recoated tool and thus the process reliability as well. To overcome this problem, macro-blasting is applied with large grains in comparison to the cemented carbide material grain size. The blasting conditions are appropriately adjusted to impose substrate material strengthening at the tooth flank too. In this way, enhanced cutting edge sharpness can be achieved after grinding (see figure $4 \mathrm{~b}$ ).

The appropriate conduct of procedures such as macro- and micro-blasting enhances the cutting performance after the tool reconditioning and improves the productivity, when using cemented carbide tools $[4,5]$. The wear behaviour of reconditioned in various ways cemented carbide hobs, macro-blasted with different grain sizes and shapes to strengthen them superficially and furthermore micro-blasted to increase the coating adhesion, is exhibited in figure 5. The micro-blasted substrates with small grain size possess, on one hand, a good adhesion with the film. On the other hand, a poor cutting performance is attained due to the development of cutting edge damages after regrinding, occurred by the reduced carbides' holding. The combination of substrate macro-blasting with large grains to impose superficial strengthening and a better WC-grains embedment before grinding and moreover, micro-blasting with small grain size to increase the film adhesion leads to a significant enhancement of the tool cutting performance.

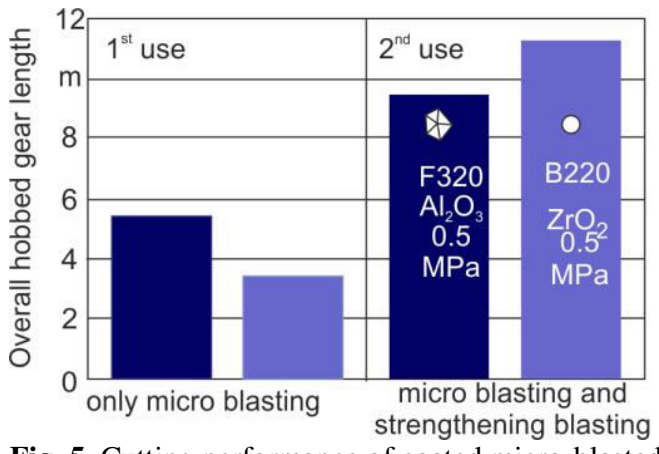

Fig. 5. Cutting performance of coated micro-blasted HM hobs, with various grain sizes and shapes. 


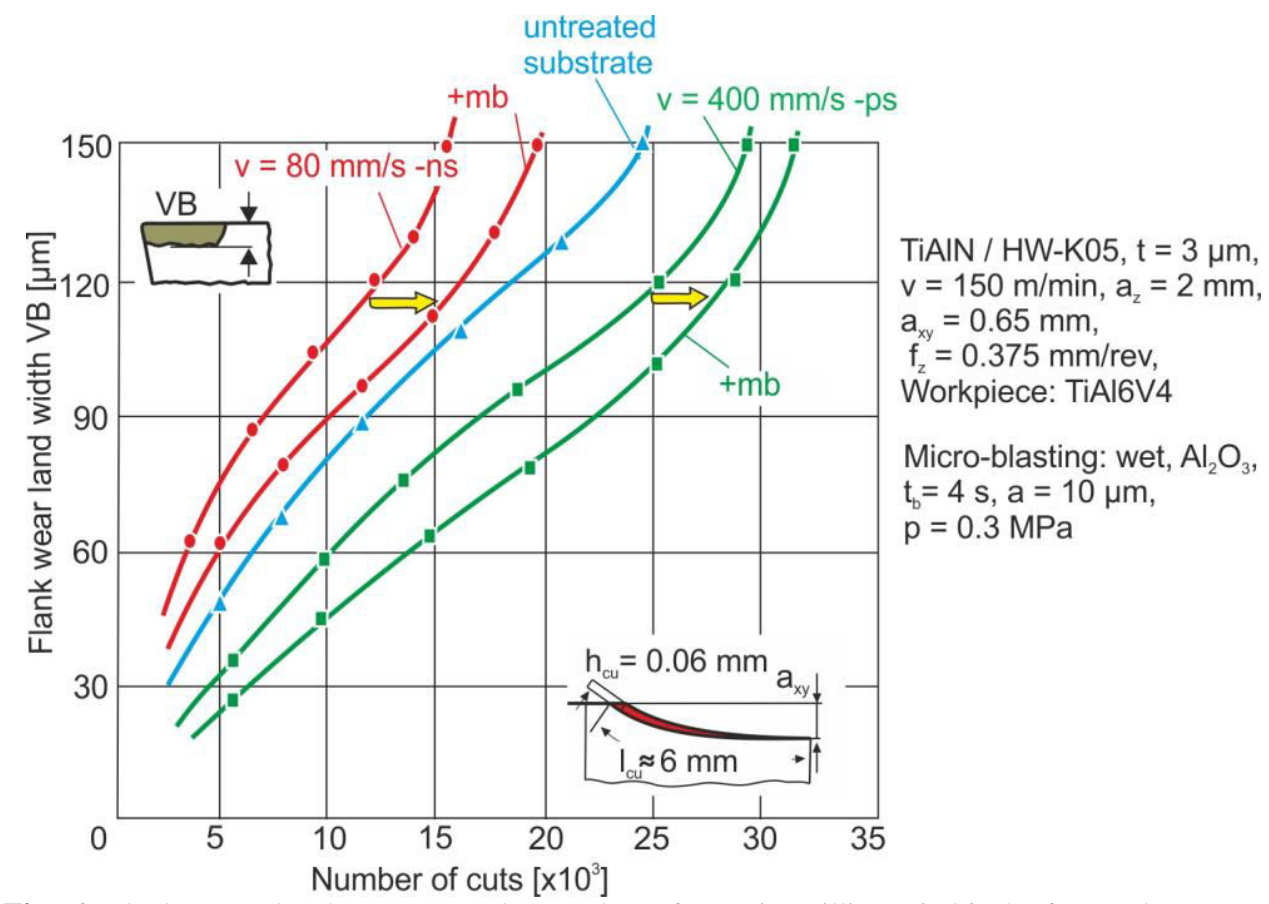

Fig. 6. Flank wear development vs. the number of cuts in milling TiAl6V4 of coated cemented carbide inserts subjected to laser-treatment or additionally to micro-blasting after the laser machining.

\subsection{Cutting performance of coated cemented carbide inserts with laser- treated and additionally micro-blasted substrates}

For releasing the carbides in the thermal affected zone (TAZ) from the cobalt binding phase of laser treated cemented carbide inserts, micro-blasting can be conducted [14]. More specifically, wet micro-blasting with $\mathrm{Al}_{2} \mathrm{O}_{3}$ grains was conducted on the cemented carbide inserts after the laser machining. For ensuring negligible substrate material removal, thus not affecting the cutting edge geometry attained by the laser treatment, the micro-blasting process lasted only $4 \mathrm{~s}$ at a pressure of $0.3 \mathrm{MPa}$ [6]. The wear evolution of coated tools with laser pre-treated and micro-blasted substrates are presented in figure 6 . When inserts subjected to nano-second pulsing laser are used, the coated tool's life is associated with approximately 150,000 cuts up to a flank wear width of $0.15 \mathrm{~mm}\left(\mathrm{NC}_{0.15}\right)$ The application of micro-blasting on the previous-mentioned cemented carbide inserts enhances $\mathrm{NC}_{0.15}$ up to approximately 200,000 cuts. A comparable coated tool life increase is also attained after micro-blasting in the case of cemented carbide substrates subjected to pico-second pulsing laser at a beam velocity of $400 \mathrm{~mm} / \mathrm{s}$. The described improvements were attained mainly due to the effective adhesion enhancement of the coating after micro-blasting [14].

\section{Coated tool's post treatments}

\subsection{Micro-blasting on PVD films}

By micro-blasting on the coated tool surfaces, residual compressive stresses are induced into the film structure, thus increasing the coating hardness, but its brittleness too. Simultaneously, abrasion phenomena are activated, which may lead to roughness increase, 

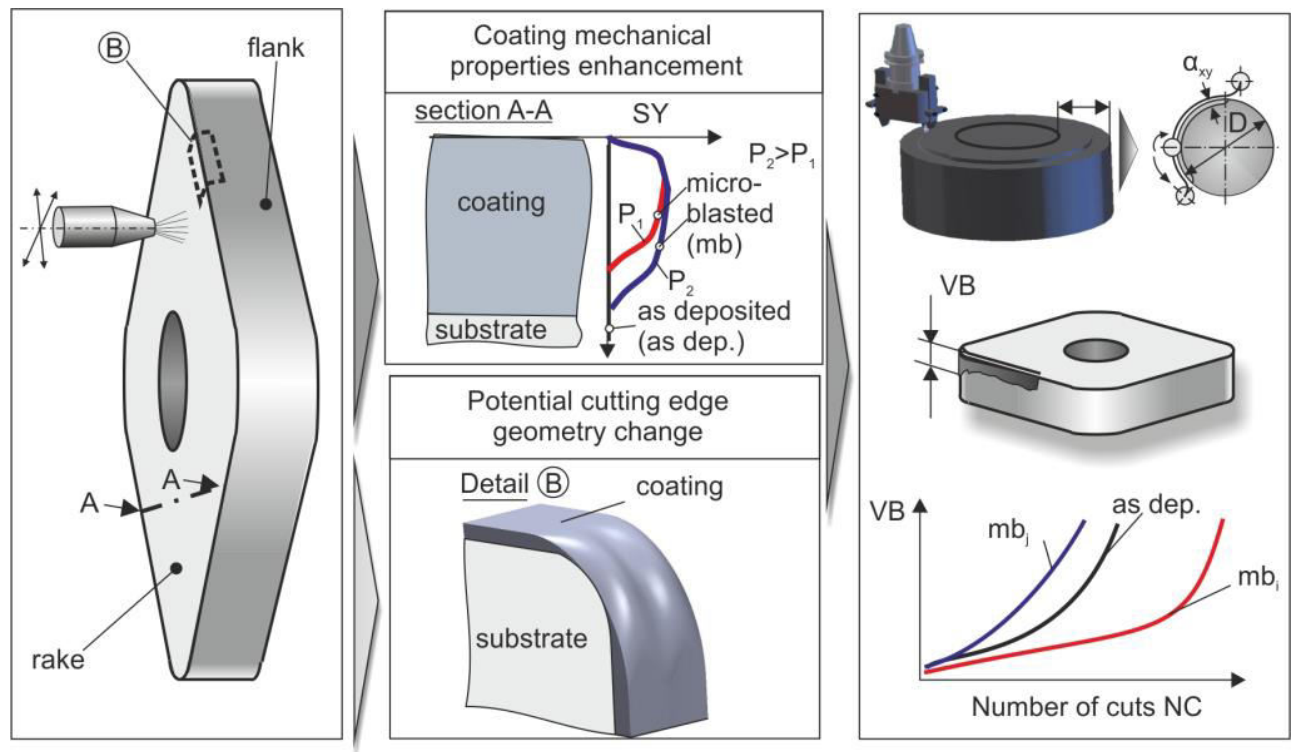

Fig. 7. Micro-blasting effects on coating's strength properties, topomorphy and tool life of coated tools.

film thickness decrease and substrate revelation. These potential effects of micro-blasting are schematically demonstrated in figure 7 and have to be taken into account for optimising the coated tools cutting performance. Micro-blasting parameters such as pressure, time as well as blasting grains' size and shape have a pivotal effect on the film strength properties and thus on the coated tools' cutting performance $[6,7,8]$.

Figure 8 explains schematically the effect of dry or wet micro-blasting by fine $\mathrm{Al}_{2} \mathrm{O}_{3}$ grains of an average diameter of approximately $10 \mu \mathrm{m}$ and by ten times larger in diameter as well, on the coated tools' surface integrity. In dry micro-blasting process (see figure 8a), a larger roughness Rt develops, if fine grains are employed. This can be explained by the repeated micro-chippings of the film's surface considering the large concentration of the fine particles, as it is schematically shown in this figure. Hence, due to the intense coating material removal, a smaller portion of the initial grain kinetic energy of the fine grains is consumed to deform plastically the coating, compared to the corresponding one by the coarser grains. In this way, coatings subjected to dry micro-blasting by $\mathrm{Al}_{2} \mathrm{O}_{3}$ grains ofan average diameter of approximately $10 \mu \mathrm{m}$ are expected to possess higher roughness and smaller nanohardness compared to micro-blasting by $\mathrm{Al}_{2} \mathrm{O}_{3}$ grains of ca. $100 \mu \mathrm{m}$ average diameter, under the same conditions.

Related mechanisms appear in the case of wet micro-blasting, as it is illustrated in figure $8 \mathrm{~b}$. Numerous fine abrasive grains are guided by water droplets at high density on the coated surface. These can cause more intense coating material removal through microchippings, for the same treatment duration compared to micro-blasting by coarse and less numerous grains per water droplet. On one hand, this happens, since the numerous small grains are dragged easier by the flowing water along the film surface, thus intensively deteriorating its roughness. On the other hand, the coarse grains are less affected by the flowing water and mainly deform the coating material. In this way, a larger portion of the initial grain kinetic energy of the coarse grains is consumed to deform plastically the coating, compared to the small ones. Thus, coatings subjected to wet micro-blasting by fine $\mathrm{Al}_{2} \mathrm{O}_{3}$ grains are expected to possess higher roughness and smaller nano-hardness, compared to the corresponding ones, micro-blasted by coarser grains under the same conditions. 

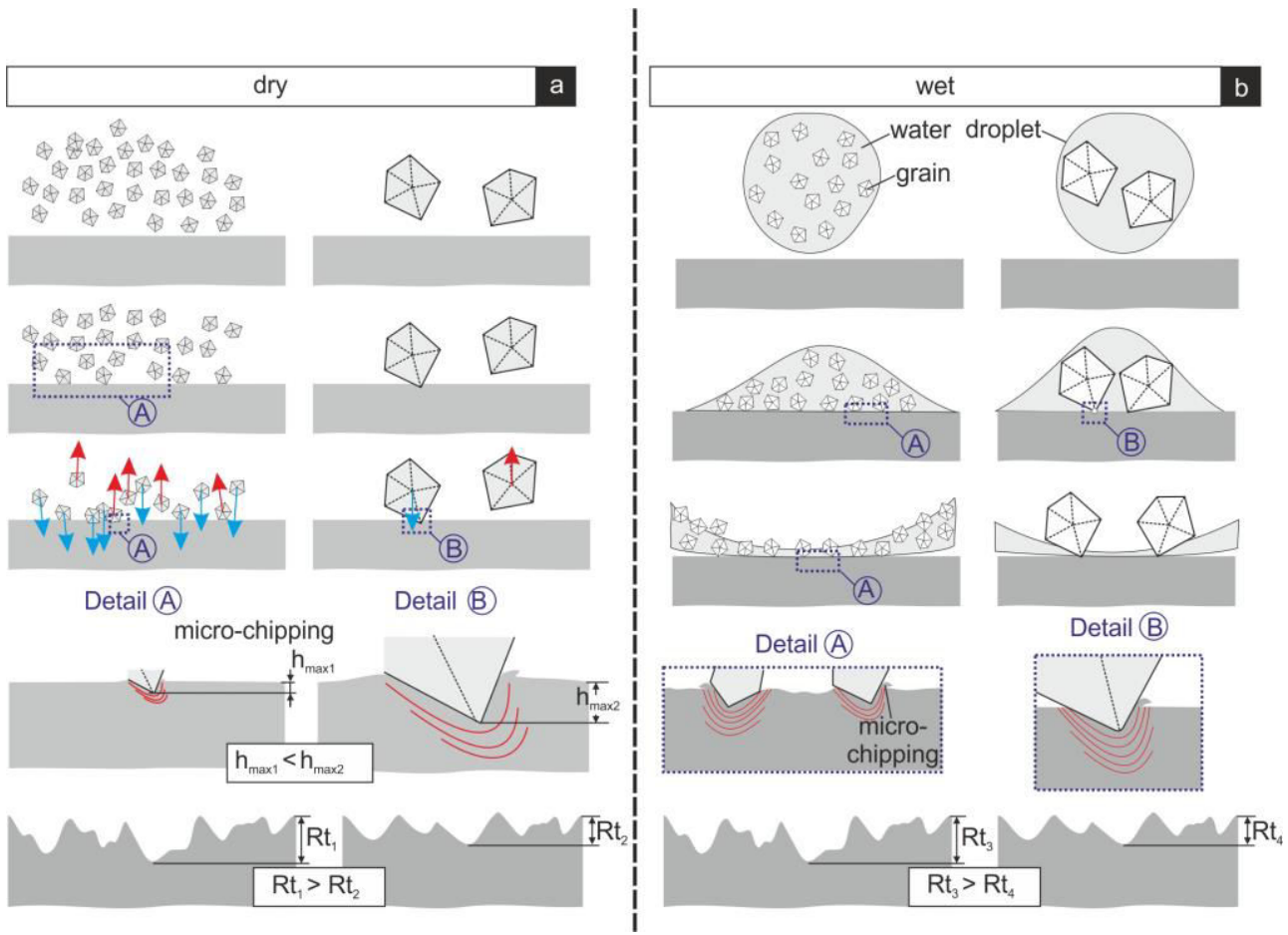

Fig. 8. Effect of abrasive grains' size and their transport medium on the surface roughness in (a) dry (b) wet micro-blasting process.

The abrasive effect exerted by dry blasting using $\mathrm{Al}_{2} \mathrm{O}_{3}$ particles is expected to be less intense for both, fine and coarse grain sizes compared to the corresponding one when a wet process is applied. In dry micro-blasting, the grains bounce from the coated surface after the impact almost perpendicular (see figure 8), thus affecting the film integrity slightly. This effect results in larger coatings' nano-hardness compared to wet micro-blasting, where the grains are dragged along the coating surface. In dry micro-basting process, the particles kinetic energy is mainly consumed to plastically deform the coating, while in the case of wet blasting, a portion of this energy is allocated to the described abrasive phenomena.

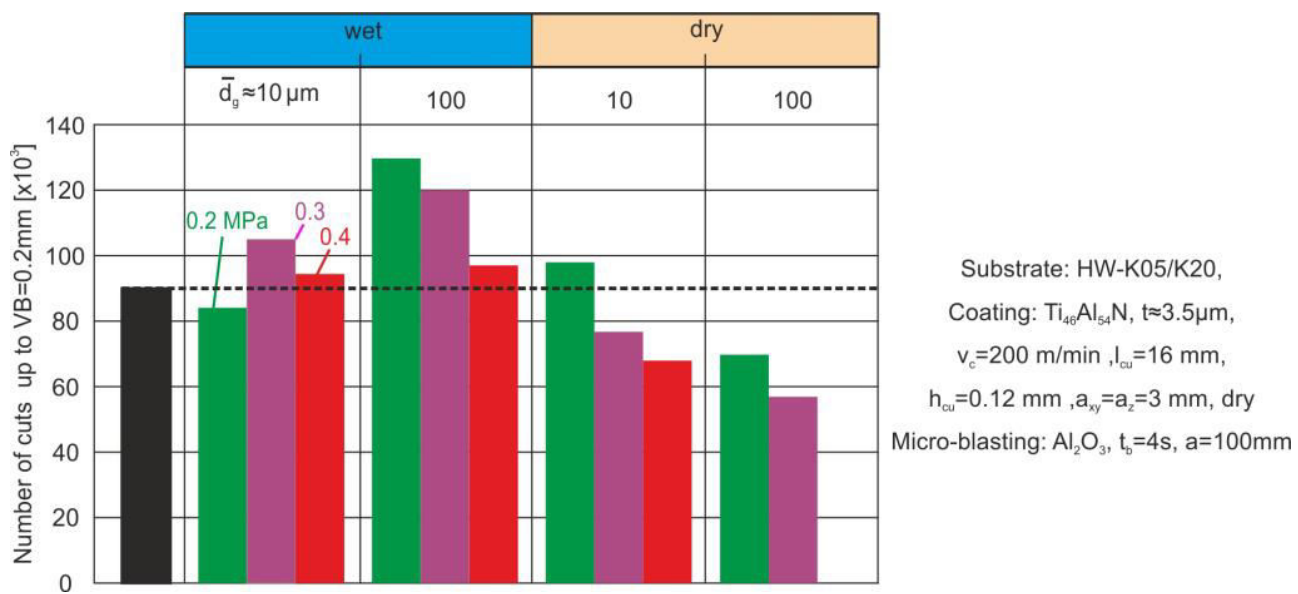

Fig. 9. Comparison of flank wear development of coated tools subjected to wet or dry micro-blasting by fine or coarse grains at different pressures. 
The achieved number of cuts up to a flank wear width of ca. $0.2 \mathrm{~mm}$ of coated tools subjected to micro-blasting by fine or coarse sharp-edged $\mathrm{Al}_{2} \mathrm{O}_{3}$ grains, employing different micro-blasting grain transport media is illustrated in figure 9. According to these results, wet micro-blasting, when coarse grains are used, contributes to coated tool cutting performance improvement. This enhancement depends on the applied micro-blasting pressure. Moreover, in the investigated cases, dry micro-blasting leads to tool wear behaviour improvement, only at low pressures and by fine grains.

\section{Conclusions}

In this paper procedures for producing coated cemented carbide tools with enhanced cutting performance were presented. The introduced processes include the conduct of micro-blasting prior to the coating deposition for improving the film adhesion. Moreover, the conduct of macro-blasting on hardmetal substrates is recommended as a procedure for reconditioning worn coated solid cemented carbide cutting tools. Finally, PVD coated inserts subjected to micro-blasting can exhibit an impressive wear resistance improvement if the related process parameters are appropriately selected.

\section{References}

1. K.-D. Bouzakis, N. Michailidis, G. Skordaris, E. Bouzakis, D. Birmann, R. M'Saoubi, CIRP Ann. Manuf. Technol. 61, 703 (2012)

2. K. Bobzin, CIRP J. Manuf. Sci. Technol. 18, 1 (2017)

3. K.-D. Bouzakis, G. Skordaris, N. Michailidis A. Asimakopoulos, G.Erkens, Surf. Coat. Technol. 200, 128 (2005)

4. K.-D. Bouzakis, G. Skordaris, S. Hadjiyiannis, A. Asimakopoulos, J. Mirisidis, N. Michailidis, G. Erkens, R. Cremer, F. Klocke, M. Kleinjans, Thin Solid Films 447 448, 264 (2004)

5. F. Klocke, T. Schroeder, E. Bouzakis, A. Klein, Surf. Coat. Technol. 202, 1194 (2007)

6. K.-D. Bouzakis, A. Tsouknidas, G. Skordaris, E. Bouzakis, S. Makrimallakis, S. Gerardis, G. Katirtzoglou, Tribology in Industry 33, 49 (2011)

7. K.-D. Bouzakis, G. Skordaris, E. Bouzakis A. Tsouknidas, S. Makrimallakis, S. Gerardis, G. Katirtzoglou, CIRP Ann. Manuf. Technol. 60, 587 (2011)

8. K.-D. Bouzakis, F. Klocke, G. Skordaris, E. Bouzakis, S. Gerardis, G. Katirtzoglou, S. Makrimallakis, Wear 271, 783 (2011)

9. C. Barbatti, J. Garci, R. Pitonak, H. Pinto, A. Kostka, A. Di Prinzio, M.H. Staia, A.R. Pyzalla, Surf. Coat. Technol. 203, 3708 (2009)

10. Canyu Liu, Zhanqiang Liu, Bing Wang, Ceram. Int. 44, 3430 (2018)

11. N. Schalk, C. Mitterer, C. Czettl, B. Sartory, M. Penoy, C. Michotte, Tribology Letters 52, 147 (2013)

12. F. Klocke, C. Gorgels, E. Bouzakis, A. Stuckenberg, Prod. Eng. Res. Devel. 3, 453 (2009)

13. A. Riedl, N. Schalk, C. Czettl, B. Sartory, C. Mitterer, WEAR 289, 9 (2012)

14. K.-D. Bouzakis, P. Charalampous, T. Kotsanis, G. Skordaris, E. Bouzakis, B. Denkena, B. Breidenstein, J.C. Aurich, M. Zimmermann, T. Herrmann, R. M'saoubi, CIRP J. Manuf. Sci. Technol. 18, 188 (2017) 